\title{
Natural Aging Effect of Al-20Zn-3Cu Alloy on Mechanical Properties and Its Relation to Microstructural Change
}

\author{
Min-Jung Park ${ }^{1,2}$, Hyeongsub So ${ }^{1,3}{ }^{\mathbb{D}}$, Kyou-Hyun Kim ${ }^{1}$, Jai-Won Byeon ${ }^{2}$ and Leeseung Kang ${ }^{1, *(D)}$ \\ 1 Korea-Russia Innovation Center, Korea Institute of Industrial Technology, Incheon 22004, Korea; \\ mjpark91@naver.com (M.-J.P.); ksd8262@gmail.com (H.S.); khkim1308@kitech.re.kr (K.-H.K.) \\ 2 Department of Materials Science and Engineering, Seoul National University of Science and Technology, \\ Seoul 01811, Korea; byeonjw@seoultech.re.kr \\ 3 Department of Materials Science and Engineering, Korea University, Seoul 02841, Korea \\ * Correspondence: leeseung@kitech.re.kr; Tel.: +82-32-458-5775
}

check for updates

Citation: Park, M.-J.; So, H.; Kim, K.-H.; Byeon, J.-W.; Kang, L. Natural Aging Effect of Al-20Zn-3Cu Alloy on Mechanical Properties and Its Relation to Microstructural Change. Metals 2021, 11, 1485. https:// doi.org/10.3390/met11091485

Academic Editor: Thomas Niendorf

Received: 20 August 2021

Accepted: 14 September 2021

Published: 18 September 2021

Publisher's Note: MDPI stays neutral with regard to jurisdictional claims in published maps and institutional affiliations.

Copyright: (C) 2021 by the authors Licensee MDPI, Basel, Switzerland This article is an open access article distributed under the terms and conditions of the Creative Commons Attribution (CC BY) license (https:// creativecommons.org/licenses/by/ $4.0 /)$.

\begin{abstract}
We investigate the effect of the natural age-hardening response of the Al-20Zn-3Cu alloy with natural aging times up to 12 months. The ultimate tensile strength of the Al-20Zn-3Cu alloy is drastically enhanced from 308 to $320 \mathrm{MPa}$ after 2 months and from 320 to $346 \mathrm{MPa}$ after 9 months. Then, natural age hardening becomes saturated after 9 months. A microstructural investigation reveals that the natural age-hardening mechanism is mainly induced by the diffusion of the $\mathrm{Zn}$ element. First, a rapid decrease in the volume fraction of the eutectoid lamellae $(\alpha-\mathrm{Al}+\eta-\mathrm{Zn})$ is observed at the early stage of natural aging, leading to an increase in the tensile strength. This originates from the relatively high diffusivity of $\mathrm{Zn}$ due to its low melting temperature. Then, the diffusion of $\mathrm{Zn}$ into the $\mathrm{Al}$ matrix induces clusters of solute atoms that enhance the growth rate of the nanoprecipitates formed in the $\mathrm{Al}$ matrix. As a consequence, the tensile strength of the natural-aged Al-20Zn-3Cu alloy increases drastically after 9 months, whereas the ductility is significantly degraded.
\end{abstract}

Keywords: natural aging; Al alloy with high Zn; mechanical properties; microstructural evolution

\section{Introduction}

Automotive components have been developed to reduce the total weight of vehicles to improve energy efficiency. For achieving the requirement, the number of $\mathrm{Al}$ alloys-based components is widely used in vehicles up to approximately 30\% [1-4]. With regard to $\mathrm{Al}$ alloys, these are mainly applied to the transmission case, wheel, engine block, converter housing, and various structural components in a chassis of vehicles [5,6]. Among several Al alloys, ADC12 (Al-Si-Cu) alloy is a conventional cast alloy applied to power train and transmission cases due to its high castability with a low shrinkage rate [7-9]. Nevertheless, ADC12 has a brittle nature because of the formation of intermetallic phase containing Si element [7,10-13]. Recently, high-Zn Al-based-alloys have attracted much research interest as a promising Al-cast alloy for automotive applications. High-Zn Al-based alloys show high strength, good wear resistance, and damping properties in comparison with such conventional cast Al-Si alloys [14-17]. In addition, the melting point of Al is gradually reduced as the amount of $\mathrm{Zn}$ increases, leading to a low production cost of the casting process [18].

In an earlier study, Shin et al. reported non-heat treatable Al-xZn-3Cu $(x=20,30,40$, 45 in $\mathrm{wt} \%$ ) alloy fabricated using the high-pressure die casting (HPDC) method [19]. Interestingly, the reported die-cast alloys exhibit a significant high tensile strength of $490 \mathrm{MPa}$ with an elongation of $\approx 4 \%$ even though any post treatments such as homogenization and artificial aging are not applied onto the alloys. These superior mechanical properties mainly stem from the unique microstructure induced by the $\mathrm{Zn}$ element while the small amount of $\mathrm{Cu}$ is also added in order to increase mechanical strength [19-21]. According to the reported binary phase diagram of $\mathrm{Al}-\mathrm{Zn}, \mathrm{Zn}$ elements can be dissolved in $\mathrm{Al}$ up to 70 
at \% for a wide range of temperatures [18]. No intermetallic compounds are formed in the $\mathrm{Al}-\mathrm{Zn}$ binary system due to the very weak chemical interaction between $\mathrm{Al}$ and $\mathrm{Zn}$ [22]. Instead, $\mathrm{Zn}$ forms very fine nanoprecipitates in the $\mathrm{Al}$ matrix and complex microstructures consisting of eutectoid lamellae ( $\alpha-\mathrm{Al}$ and $\eta-\mathrm{Zn})$ and the $\mathrm{Zn}$ phase in the vicinity of the grain boundaries $[19,23,24]$. This complex microstructure is more developed as the amount of $\mathrm{Zn}$ increases such that the mechanical strength of high-Zn Al-based alloys is correspondingly enhanced according to the amount of $\mathrm{Zn}$.

On the other hand, it has been reported that the $\mathrm{Zn}$ element in $\mathrm{Al}$ alloy strongly affects mechanical properties during natural aging [25]. In earlier work, a 3DAP (threedimensional atom probe) analysis demonstrated that the $\mathrm{Zn}$ element enhances the growth rate of clusters in the Al matrix during natural aging, leading to the segregation of solute atoms from the $\mathrm{Al}$ matrix into clusters [26]. Then, by natural aging over time, the number density and volume fraction of clusters are the major factors to increase mechanical strength [27].

Therefore, based on the above considerations, it is evident that the natural aging response of high-Zn Al-based alloys should be carefully considered when developing Al-cast alloys for the applications in automotive components. In this study, we investigated the effect of natural aging on the microstructural evolution and its resultant mechanical properties of high-Zn Al-based alloys. For the purpose, the Al-20Zn-3Cu alloy was selected as the representative alloy to demonstrate the natural aging response in high-Zn Al-based alloy. The Al-20Zn-3Cu alloy was prepared using a conventional gravity casting method. Then, the as-cast specimen was naturally aged up to 9 months, and the variations of the mechanical properties were investigated based on structural investigations.

\section{Experimental Procedures}

Table 1 shows the nominal compositions of the synthesized Al-20Zn-3Cu alloys. Highpurity metals $(\mathrm{Al}, \mathrm{Cu}, \mathrm{Zn})$ and master alloys (Al-5 $\mathrm{wt} \% \mathrm{Ti}, \mathrm{Al}-5 \mathrm{wt} \% \mathrm{Fe}$, and $\mathrm{Al}-12 \mathrm{wt} \%$ $\mathrm{Zr}$ ) were used to fabricate the developed alloys. Additionally, minor elements of $\mathrm{Cu}, \mathrm{Si}$, $\mathrm{Fe}, \mathrm{Ti}$, and $\mathrm{Zr}$ were added to enhance the castability and mechanical properties. The alloy components were melted in an electric resistance furnace at $730{ }^{\circ} \mathrm{C}$. Then, the molten alloy was degassed using $\mathrm{N}_{2}$ gas and stabilized in the furnace at $700{ }^{\circ} \mathrm{C}$ for $30 \mathrm{~min}$. Alloy ingots were finally fabricated using a gravity casting method at room temperature. Then, the as-cast specimens were naturally aged for 2 months, 9 months, and 12 months at room temperature. Tensile tests were performed using a universal testing machine (UTM, DEAKYUNG TECH. \& TESTER Mfg. Co., Ltd., DTU-900MHN, Incheon, Republic of Korea) with a constant strain rate of $1 \mathrm{~mm} / \mathrm{min}$ at room temperature. All test specimens were prepared based on the ASTM E8 standard (Standard Test Method for the Tensile Testing of Metal Materials) [28]. Tensile tests were performed at least ten times for each alloy in order to obtain average values.

Table 1. Chemical compositions of Al-20Zn-3Cu alloys (in $w \mathrm{t} \%$ ).

\begin{tabular}{cccccccc}
\hline Alloy & Zn & Cu & Ti & Zr & Fe & Si & Al \\
\hline Al-20Zn-3Cu & 20 & 3.0 & 0.1 & 0.1 & 0.5 & 0.4 & Bal. \\
\hline
\end{tabular}

On the macroscopic scale, the microstructures of synthesized alloys were investigated using an optical microscope (OM, KEYENCE Co., Ltd., VHX-1000E, Osaka, Japan). Then, phase identification was done using X-ray diffraction (XRD, BRUKER Co., D8 ADVANCE, Billerica, MA, USA) having a resolution of $0.01^{\circ}$ in $2 \theta$. The microscopic structures were studied in detail using a field-emission scanning electron microscopy (FE-SEM, JEOL Ltd., JSM-7100F, Akishima, Japan) with an energy-dispersive X-ray spectroscopy (EDXS) detector. The local nanoscopic microstructure was further investigated using a transmission electron microscope (FE-TEM, FEI Company, TECNAI ST-F20, Hillsboro, WA, USA). The 
TEM specimens were mechanically polished down to 10-15 $\mu \mathrm{m}$ and then Ar-ion milled at an acceleration voltage of $4 \mathrm{kV}$ with an incident angle of $6^{\circ}$ for electron transparency.

\section{Results and Discussion}

Figure 1 shows the tensile properties of $\mathrm{Al}-20 \mathrm{Zn}-3 \mathrm{Cu}$ at different natural aging times from as-cast to 12 months. As reported earlier, the Al-20Zn-3Cu alloy shows fracture strength $\left(\sigma_{\mathrm{f}}\right)$ of $308 \mathrm{MPa}$ with elongation of $\varepsilon_{\mathrm{f}}=\approx 6 \%$. For the natural aging response, the tensile strength of $\mathrm{Al}-20 \mathrm{Zn}-3 \mathrm{Cu}$ alloy is naturally aged from $\sigma_{\mathrm{f}}=304( \pm 3.83) \mathrm{MPa}$ to $\sigma_{\mathrm{f}}=320( \pm 4.28) \mathrm{MPa}$ after 2 months with a slight decrease in the elongation from 6.5 $( \pm 1.30) \%$ to $5.4( \pm 0.87) \%$. After 9 months, the tensile strength improves drastically to $\approx 346$ $( \pm 6.72) \mathrm{MPa}$ with a significant reduction in the degree of elongation at $\approx 1.2( \pm 0.64) \%$. Then, it mostly plateaus around $\sigma_{\mathrm{f}}=346 \mathrm{MPa}$ with a similar elongation rate of $\approx 1.2 \%$.

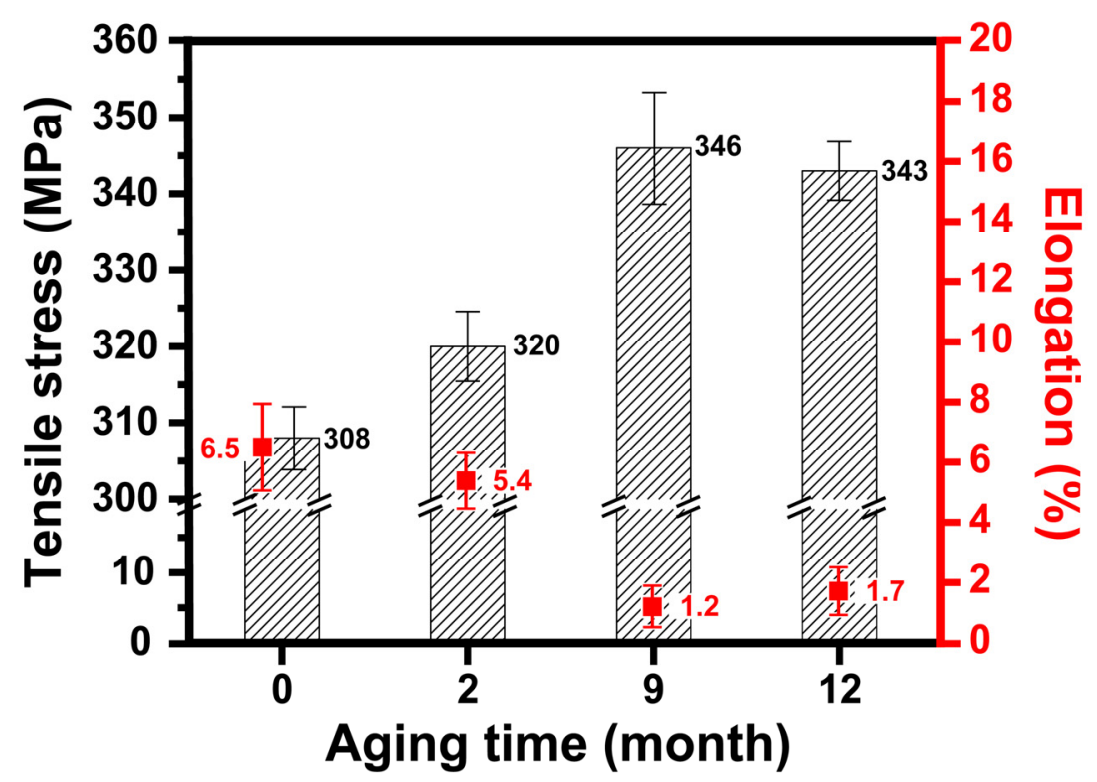

Figure 1. Fracture strength and elongation of $\mathrm{Al}-20 \mathrm{Zn}-3 \mathrm{Cu}$ with respect to the natural aging time for the as-cast sample and those at 2 months, 9 months, and 12 months.

Figure 2 shows the $2 \theta$ scan profiles recorded by XRD from the Al-20Zn-3Cu alloy for different natural aging times. The XRD profiles consist of the strongest major peaks of $\alpha$-Al with the weak peaks for second phases that formed in the synthesized alloys. In the as-cast $\mathrm{Al}-20 \mathrm{Zn}-3 \mathrm{Cu}$ alloy, the major peaks of $\mathrm{Al}$ are found at $2 \theta$ values of $38.64^{\circ} / 44.89^{\circ}$, which can be indexed as $\{111\}_{\mathrm{Al}}$ for $38.64^{\circ}$ and $\{200\}_{\mathrm{Al}}$ for $44.89^{\circ}$. The experimental $2 \theta$ values are compared with the calculated $2 \theta$ values based on the reported crystallographic information of $\mathrm{Al}(\mathrm{fcc}, F m \overline{3} m, 225)$. The calculated $2 \theta$ values of $\{111\}_{\mathrm{Al}}$ and $\{200\}_{\mathrm{Al}}$ are respectively $38.472^{\circ}$ and $44.738^{\circ}$. Considering the experimental $2 \theta$ values of $\mathrm{Al}$, the peaks are slightly shifted to a higher $2 \theta$ angle, indicating the existence of compressive strain in the Al matrix. This may stem from the residual stress induced during the solidification process due to the high content of $\mathrm{Zn}$ element, which is often observed in a gravity-cast processing of high- $\mathrm{Zn}$-based $\mathrm{Al}$ alloys. The major peaks of $\mathrm{Al}$ are constant regardless of the natural aging time. This indicates that the residual stress existing in the Al matrix is not affected by the level of natural aging. For the weak XRD peaks, the as-cast Al-20Zn-3Cu alloy consists of the secondary phases of $\mathrm{Zn}$ (hcp, P63/mmc, 194), $\mathrm{Cu}$ (fcc, $F m \overline{3} m, 225), \mathrm{Al}_{3} \mathrm{Zr}$ (tetragonal, $I 4 / \mathrm{mmm}, 139$ ), and $\mathrm{Al}_{2} \mathrm{Cu}$ (tetragonal, $\mathrm{I} 4 / \mathrm{mcm}, 140$ ), which are determined using the reported crystallographic information. On the other hand, the peak intensities of the secondary phases gradually change with longer natural aging times. In the XRD profiles of the Al-20Zn-3Cu alloy, the peak related to the $\mathrm{Zn}$ phase abruptly decreases after 2 months, while other secondary peaks remain nearly identical. The configuration of the XRD scan profile shows no distinct changes after 9 months. As shown in Figure 1, the 
natural age-hardening response is observed after 2 months of natural aging. Therefore, considering the XRD profiles, the microstructural changes observed in the XRD profiles are closely related to the mechanical properties.

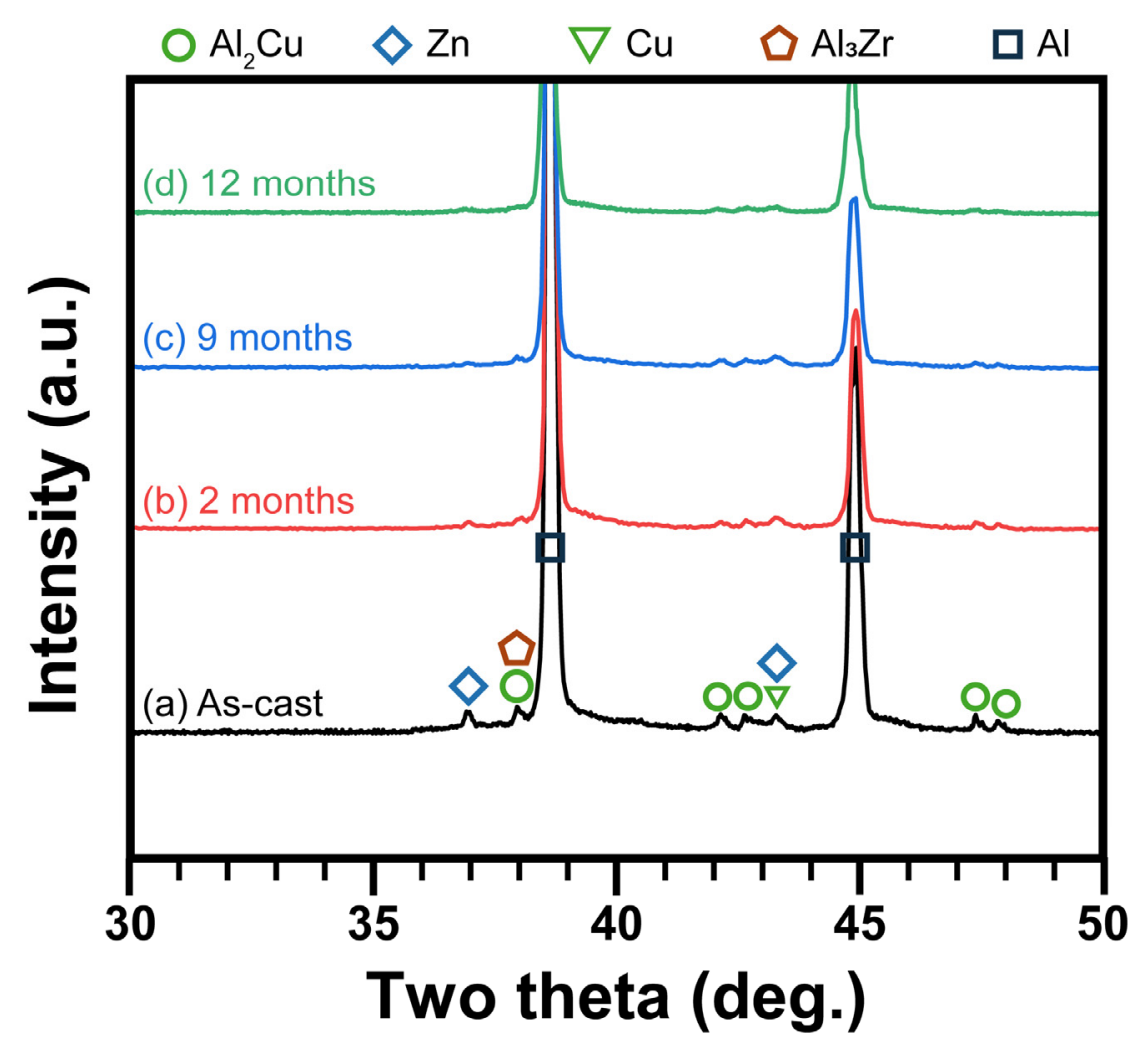

Figure 2. XRD profiles of the $\mathrm{Al}-20 \mathrm{Zn}-3 \mathrm{Cu}$ alloy at different natural aging times.

Figure 3 shows back-scattered electron (BSE) images of Al-20Zn-3Cu with respect to the natural aging times. For the as-cast $\mathrm{Al}-2 \mathrm{Zn}-3 \mathrm{Cu}$ alloy (Figure 3a), as reported in a previous study [19], the grain boundary regions of the Al-20Zn-3Cu alloy mainly consists of pure $\mathrm{Cu}$ and a complex lamellae structure, respectively indicated as I and II in Figure 3a. The inset of Figure $3 \mathrm{a}$ is a magnified image of the complex lamellae structure consisting of $\alpha-\mathrm{Al}$ and $\eta(\mathrm{Zn}, \mathrm{HCP})$. This microstructure is still observed after 2 months, as shown in the inset of Figure $3 \mathrm{~b}$. However, the volume fraction of the complex lamellae structure decreases drastically after 9 months, as shown in Figure 3c,d. As demonstrated earlier, the eutectoid lamellae in the grain boundaries impedes the crack propagation, resulting in the increase in elongation of Al-20Zn-3Cu alloy [19]. Therefore, the significant decrease in elongation shown in Figure 1 is considered to be a result from the significant reduction eutectoid lamellae in the grain boundaries of $\mathrm{Al}-20 \mathrm{Zn}-3 \mathrm{Cu}$ alloy. 


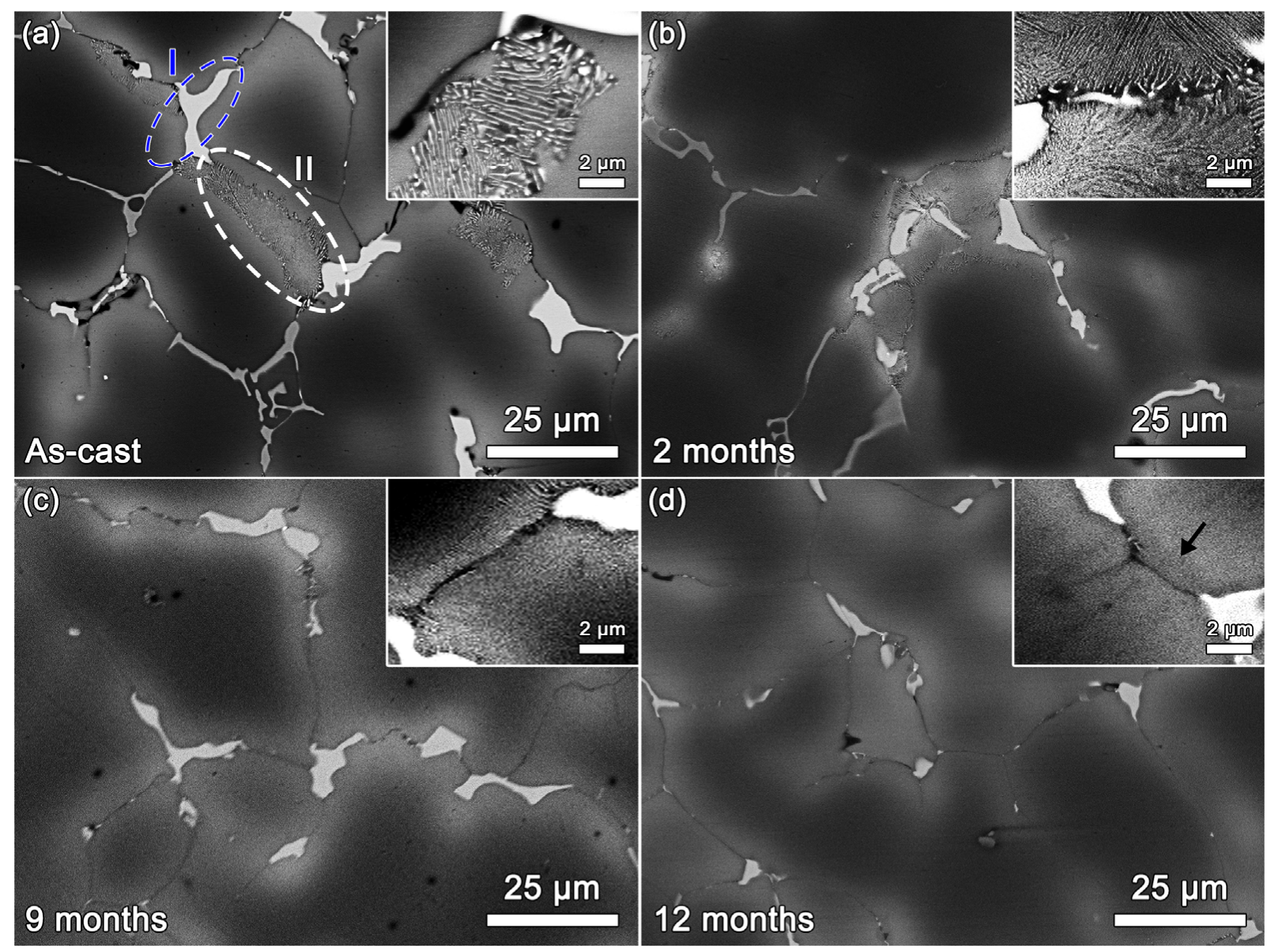

Figure 3. Typical BSE images of Al-20Zn-3Cu: (a) as-cast, (b) 2 months, (c) 9 months, and (d) 12 months. The insets show the decreased volume fraction of the eutectoid lamellar structure consisting of the $\alpha-\mathrm{Al}$ and the $\eta-\mathrm{Zn}$ phase.

Figure 4 shows the elemental mapping results of $\mathrm{Al}-20 \mathrm{Zn}-3 \mathrm{Cu}$ for the different natural aging times. In the as-cast $\mathrm{Al}-20 \mathrm{Zn}-3 \mathrm{Cu}$ alloy, the $\mathrm{Cu}$ and $\mathrm{Zn}$ elements are mostly found in the vicinity of the grain boundaries, correspondingly indicated here by I and II, as shown in Figure 4a. As demonstrated in the BSE images (Figure 3), the $\mathrm{Cu}$ and $\mathrm{Zn}$ elements found in the grain boundaries form large particles of pure $\mathrm{Cu}$ and eutectoid lamellae consisting of $\mathrm{Al}$ and $\mathrm{Zn}$ phases. The elemental mapping outcome of the $\mathrm{Al}-20 \mathrm{Zn}-3 \mathrm{Cu}$ alloy indicates that the $\mathrm{Zn}$ constituents gradually migrate into the $\mathrm{Al}$ matrix with longer natural aging times. Thus, a decrease in the $\mathrm{Zn}$ element leads to a decrease in the volume fraction of the $\eta$ phase in the grain boundaries, resulting in a decrease in the eutectoid lamellae structures, as demonstrated in Figure 3a-d. It was reported that $\mathrm{Zn}$-contained alloy is naturally aged even at room temperature due to the relatively high diffusivity of $\mathrm{Zn}$. This originates from the low melting point of $\mathrm{Zn}$. Resultantly, the $\mathrm{Zn}$-added Al alloys show enhanced natural age-hardening responses compared to a Zn-free alloy [26,29]. In contrast to the $\mathrm{Zn}$ element, the large $\mathrm{Cu}$ particles show no obvious changes in the naturally aged $\mathrm{Al}-20 \mathrm{Zn}-3 \mathrm{Cu}$ alloy. Hence, the increase in the tensile strength of the Al-20Zn-3Cu alloy after 2 months is considered to originate from the decrease in the eutectoid lamella structures in the vicinity of the grain boundaries. However, after 2 months of natural aging time, the volume fraction of the eutectoid lamellae slowly decreases such that the enhancement of the tensile strength after 2 months of natural aging time should be considered at microscopic scale. This will be discussed further in conjunction with the results of the TEM investigation. 

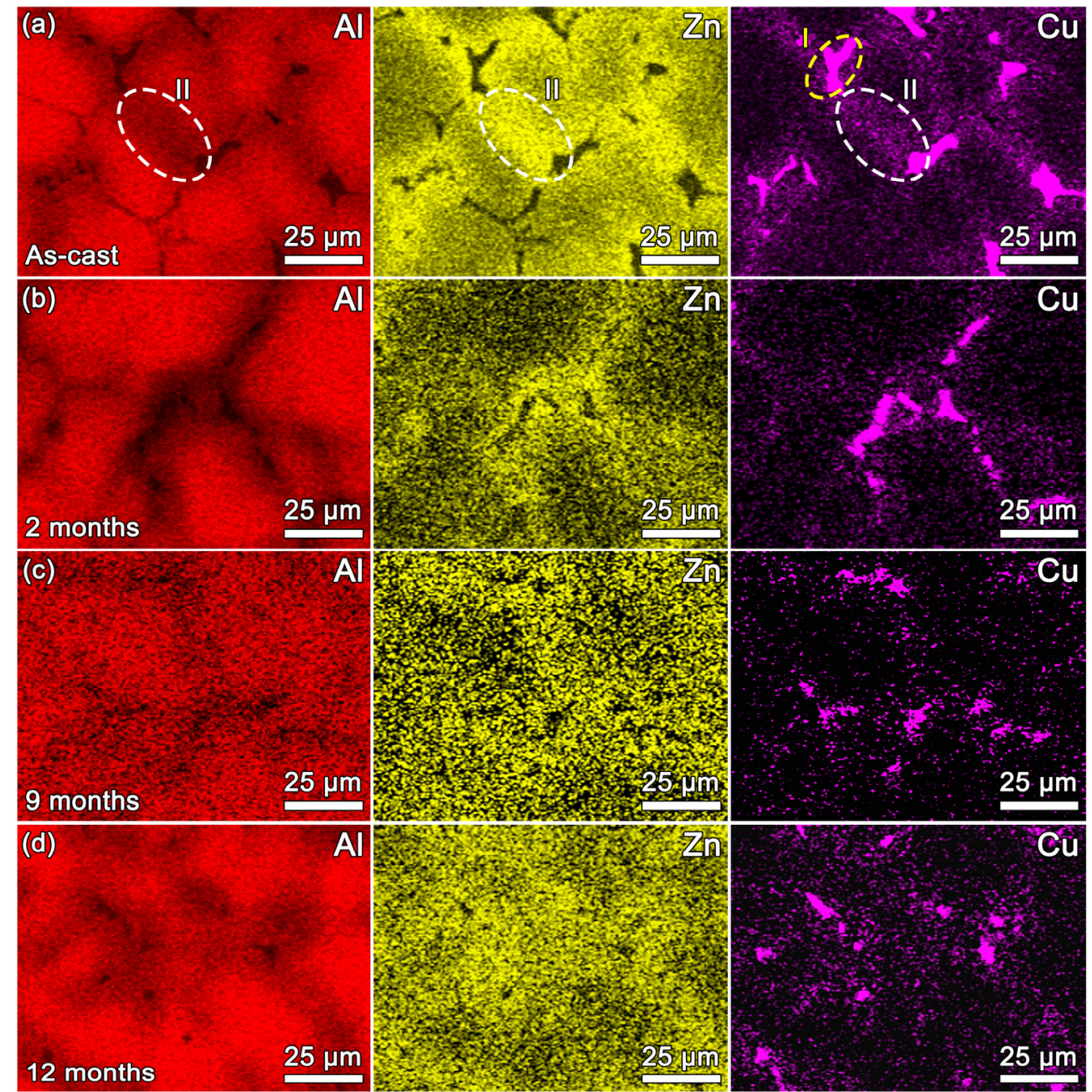

Figure 4. Elemental mapping results of Al-20Zn-3Cu: (a) as-cast, (b) 2 months, (c) 9 months, and (d) 12 months. Area I and II respectively indicate the pure $\mathrm{Cu}$ and the eutectoid lamellar structure.

Figure 5 shows Z-contrast images of the Al-20Zn-3Cu alloys according to the natural aging times, in this case as-cast and 9 months. As shown in Figure $5 a, b$, the Al-20Zn$3 \mathrm{Cu}$ alloy consists of very fine nanoprecipitates. Two types of nanoprecipitates can be observed in the $\alpha$-Al matrix of the $\mathrm{Al}-20 \mathrm{Zn}-3 \mathrm{Cu}$ alloy, as indicated by the I and II arrows in Figure 5a. A chemical investigation showed that the nanoprecipitates I and II are respectively composed of a $\mathrm{Zn}$-Cu-rich and a Zn-rich phase. More details of phase identification can be found elsewhere [30]. Nanoprecipitate I ( $\mathrm{Zn}$-Cu-rich phase) has average dimensions of $\approx 5 \times 15 \mathrm{~nm}^{2}$ in terms of the length and width, while nanoprecipitate II (Zn-rich phase) has an average diameter of $\approx 3 \mathrm{~nm}$. Due to the very fine sizes of these nanoprecipitates, the corresponding [110] electron diffraction (ED) pattern has no distinct patterns of the nanoprecipitates that formed in the $\alpha-\mathrm{Al}$ matrix. Similarly, as shown in Figure $5 \mathrm{~b}$, the morphology of nanoprecipitates in the $\alpha-\mathrm{Al}$ matrix shows no significant change after 2 months of natural aging time. In contrast, severe microstructural evolution is observed after 9 months of natural aging time. As shown in Figure $5 c$, fine nanoprecipitates of $\mathrm{Zn}-\mathrm{Cu}$-rich and $\mathrm{Zn}$-rich phases drastically grow compared to the as-cast $\mathrm{Al}-20 \mathrm{Zn}-3 \mathrm{Cu}$ alloy. Accordingly, the satellite electron spots around the election spots in the $\alpha$-Al matrix are evidence of the coarsened nanoprecipitates. 

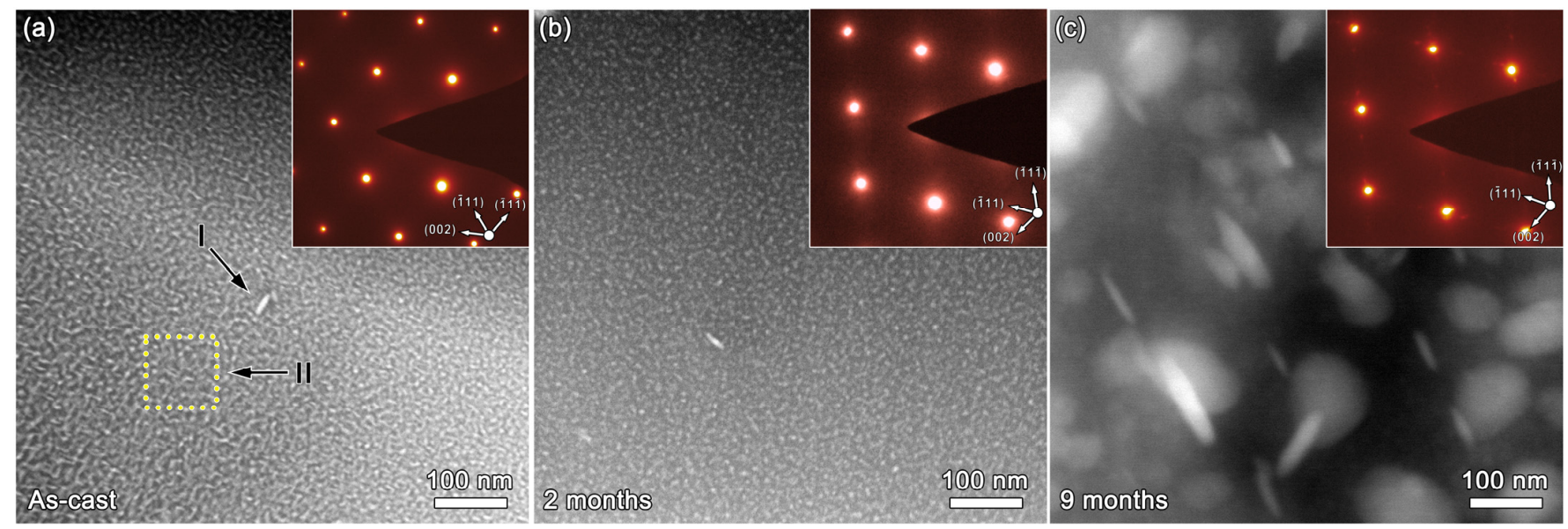

Figure 5. Typical Z-contrast images respectively recorded from (a) as-cast, (b) 2 months, and (c) 9 months natural-aged Al-20Zn-3Cu alloys. Corresponding electron diffraction patterns are presented in the insets.

Considering the above, in consequence, the change in the mechanical properties of the Al-20Zn-3Cu alloy (Figure 1) is strongly affected by the diffusion of $\mathrm{Zn}$ into the $\mathrm{Al}$ matrix. The diffusivity of $\mathrm{Zn}$ element is known to be relatively high at room temperature due to the low melting point of $\mathrm{Zn}$ [29], meaning that natural aging proceeds spontaneously. In addition, it has been reported that the $\mathrm{Zn}$ element accelerates the aggregation of clusters in the Al matrix [26], which enhances the strength and lowers the ductility. The decrease in the $\mathrm{Zn}$ phase can also be confirmed from the XRD profiles shown in Figure 2. The amount of the $\mathrm{Zn}$ phase obviously decreases after 2 months of natural aging in the Al-20Zn-3Cu alloys. As demonstrated in Figure 5, the clusters are induced by the $\mathrm{Zn}$ element in the growth of nanoprecipitates with an increase in the natural aging time.

\section{Conclusions}

In this study, we investigated the effects of natural aging on the tensile properties of the $\mathrm{Al}-20 \mathrm{Zn}-3 \mathrm{Cu}$ alloy. It was demonstrated that the change of tensile properties according to natural aging times resulted from the microstructural evolution of $\mathrm{Al}-20 \mathrm{Zn}-3 \mathrm{Cu}$ alloy. The microstructural change is caused by the relatively high diffusivity of the Zn element at room temperature. First, the diffusion of the $\mathrm{Zn}$ element from the grain boundaries into the $\alpha$-Al matrix induces a decrease in the volume fraction of large eutectoid structures consisting of the $\alpha-\mathrm{Al}$ and $\eta(\mathrm{Zn})$ phases in the $\mathrm{Al}-20 \mathrm{Zn}-3 \mathrm{Cu}$ alloy with 2 months of natural aging. As a result, the tensile strength of the Al-20Zn-3Cu alloy increases from 308 to $320 \mathrm{MPa}$. As the natural aging grows longer, gradual $\mathrm{Zn}$ diffusion facilitates the formation of clusters in the $\alpha$-Al matrix, causing the size of the nanoprecipitates in the $\mathrm{Al}-20 \mathrm{Zn}-3 \mathrm{Cu}$ alloy to increase drastically, which is very similar to the effect of the peak-aging process. Then, the significant growth of nanoprecipitates enables the highest tensile strength of $\approx 346 \mathrm{MPa}$ in the $\mathrm{Al}-20 \mathrm{Zn}-3 \mathrm{Cu}$ alloy with significantly reduced ductility by approximately $1 \%$.

Author Contributions: Conceptualization, L.K.; investigation, M.-J.P. and H.S.; data curation, H.S.; writing—original draft preparation, M.-J.P. and K.-H.K.; writing—review and editing, L.K.; project administration, K.-H.K.; resources, J.-W.B.; supervision, J.-W.B. and L.K.; funding acquisition, K.-H.K. All authors have read and agreed to the published version of the manuscript.

Funding: This research was financially supported by the Institute of Civil Military Technology Cooperation funded by the Defense Acquisition Program Administration and by the Ministry of Trade, Industry, and Energy of the Korean government under Grant No. UM18206RD2. This study was also equally supported by the R\&D program from the Korea Institute of Industrial Technology.

Institutional Review Board Statement: Not applicable.

Informed Consent Statement: Not applicable. 
Data Availability Statement: The raw/processed data required to reproduce these findings cannot be shared at this time as the data also forms part of an ongoing study.

Conflicts of Interest: The authors declare no conflict of interest.

\section{References}

1. Wenlong, S.; Xiaokai, C.; Lu, W. Analysis of energy saving and emission reduction of vehicles using light weight materials. Energy Procedia 2016, 88, 889-893. [CrossRef]

2. Long, R.S.; Boettcher, E.; Crawford, D. Current and future uses of aluminum in the automotive industry. JOM 2017, 69, 2635-2639. [CrossRef]

3. Bandivadekar, A.; Bodek, K.; Cheah, L.; Evans, C.; Groode, T.; Heywood, J.; Kasseris, E.; Kromer, M.; Weiss, M. On the Road in 2035: Reducing Transportation's Petroleum Consumption and GHG Emissions; Massachusetts Institute of Technology: Cambridge, MA, USA, 2008

4. Yılmaz, T.G.; Tüfekçi, M.; Karpat, F. A study of lightweight door hinges of commercial vehicles using aluminum instead of steel for sustainable transportation. Sustainability 2017, 9, 1661. [CrossRef]

5. Kaufman, J.G.; Rooy, E.L. Aluminum Alloy Castings; ASM International: Geauga, OH, USA, 2004.

6. Shin, J.; Kim, T.; Kim, D.E.; Kim, D.; Kim, K. Castability and mechanical properties of new 7xxx aluminum alloys for automotive chassis/body applications. J. Alloys Compd. 2017, 698, 577-590. [CrossRef]

7. Okayasu, M.; Ohkura, Y.; Takeuchi, S.; Takasu, S.; Ohfuji, H.; Shiraishi, T. A study of the mechanical properties of an Al-Si-Cu alloy (ADC12) produced by various casting processes. Mater. Sci. Eng. A 2012, 543, 185-192. [CrossRef]

8. Hu, X.; Jiang, F.; Ai, F.; Yan, H. Effects of rare earth Er additions on microstructure development and mechanical properties of die-cast ADC12 aluminum alloy. J. Alloys Compd. 2012, 538, 21-27. [CrossRef]

9. Zhao, H.D.; Wang, F.; Li, Y.Y.; Xia, W. Experimental and numerical analysis of gas entrapment defects in plate ADC12 die castings. J. Mater. Process. Technol. 2009, 209, 4537-4542. [CrossRef]

10. Hangai, Y.; Kamada, H.; Utsunomiya, T.; Kitahara, S.; Kuwazuru, O.; Yoshikawa, N. Tensile properties and fracture behavior of aluminum alloy foam fabricated from die castings without using blowing agent by friction stir processing route. Materials 2014, 7, 2382-2394. [CrossRef]

11. Singh, H.; Kumar, S.; Kumar, D.; Srivastav, M.; Kumar, R.; Jain, J.; Chouhan, A.; Khatri, O.P. Reinforcing the Near Eutectic Aluminum-Silicon Alloy with Graphene: An Approach toward Self-Lubricating Composite. Adv. Eng. Mater. 2021, 23, 2000910. [CrossRef]

12. Okayasu, M.; Sato, R.; Takasu, S.; Niikura, A.; Shiraishi, T. Mechanical properties of AlSiCu alloys produced by the twin rolled continuous casting process. Mater. Sci. Eng. A 2012, 534, 614-623. [CrossRef]

13. Khalifa, W.; Tsunekawa, Y.; Okumiya, M. Effect of ultrasonic treatment on the Fe-intermetallic phases in ADC12 die cast alloy. J. Mater. Process. Technol. 2010, 210, 2178-2187. [CrossRef]

14. Chen, Y.; Liu, C.Y.; Ma, Z.Y.; Huang, H.F.; Peng, Y.H.; Hou, Y.F. Effect of Sc addition on the microstructure, mechanical properties, and damping capacity of Al-20Zn alloy. Mater. Charact. 2019, 157, 109892. [CrossRef]

15. Jiang, H.J.; Liu, C.Y.; Chen, Y.; Yang, Z.X.; Huang, H.F.; Wei, L.L.; Li, Y.B.; Qi, H.Q. Evaluation of microstructure, damping capacity and mechanical properties of Al-35Zn and Al-35Zn-0.5Sc alloys. J. Alloys Compd. 2018, 739, 114-121. [CrossRef]

16. Shin, S.S.; Lim, K.M.; Park, I.M. Effects of high Zn content on the microstructure and mechanical properties of Al-Zn-Cu gravity-cast alloys. Mater. Sci. Eng. A 2017, 679, 340-349. [CrossRef]

17. Krajewski, W.K.; Greer, A.L.; Buraś, J.; Piwowarski, G.; Krajewski, P.K. New developments of high-zinc Al-Zn-Cu-Mn cast alloys. Mater. Today Proc. 2019, 10, 306-311. [CrossRef]

18. Murray, J.L. The Al-Zn (aluminum-zinc) system. Bull. Alloy Phase Diagr. 1983, 4, 55-73. [CrossRef]

19. Shin, S.S.; Won, S.J.; So, H.; Lee, S.K.; Kim, K.H. High-Strength Al-Zn-Cu-Based Alloy Synthesized by High-Pressure Die-Casting Method. Metall. Mater. Trans. A 2020, 51, 6630-6639. [CrossRef]

20. Chinh, N.Q.; Lendvai, J.; Ping, D.H.; Hono, K. The effect of $\mathrm{Cu}$ on mechanical and precipitation properties of $\mathrm{Al}-\mathrm{Zn}-\mathrm{Mg}$ alloys. J. Alloys Compd. 2004, 378, 52-60. [CrossRef]

21. Alemdağ, Y.; Savaşkan, T. Mechanical and tribological properties of Al-40Zn-Cu alloys. Tribol. Int. 2009, 42, 176-182. [CrossRef]

22. Skoko, Z.; Popović, S.; Štefanić, G. Microstructure of Al-Zn and Zn-Al Alloys. Croat. Chem. Acta 2009, 82, 405-419.

23. Krajewski, W.K.; Buraś, J.; Krajewski, P.K.; Greer, A.L.; Faerber, K.; Schumacher, P. New developments of Al-Zn cast alloys. Mater. Today Proc. 2015, 2, 4978-4983. [CrossRef]

24. Zhou, W.B.; Teng, G.B.; Liu, C.Y.; Qi, H.Q.; Huang, H.F.; Chen, Y.; Jiang, H.J. Microstructures and Mechanical Properties of Binary Al-Zn Alloys Fabricated by Casting and Heat Treatment. J. Mater. Eng. Perform. 2017, 26, 3977-3982. [CrossRef]

25. Guo, M.X.; Zhang, Y.; Zhang, X.K.; Zhang, J.S.; Zhuang, L.Z. Non-isothermal precipitation behaviors of Al-Mg-Si-Cu alloys with different Zn contents. Mater. Sci. Eng. A 2016, 669, 20-32. [CrossRef]

26. Zhu, S.; Li, Z.H.; Yan, L.Z.; Li, X.W.; Huang, S.H.; Yan, H.W.; Zhang, Y.G.; Xiong, B.Q. Natural aging behavior in pre-aged Al-Mg-Si-Cu alloys with and without Zn addition. J. Alloys Compd. 2019, 773, 496-502. [CrossRef]

27. Cao, L.F.; Rometsch, P.A.; Couper, M.J. Clustering behaviour in an Al-Mg-Si-Cu alloy during natural ageing and subsequent under-ageing. Mater. Sci. Eng. A 2013, 559, 257-261. [CrossRef]

28. ASTME. Standard Test Methods for Tension Testing of Metallic Materials; ASTME: West Conshohocken, PA, USA, 2001. 
29. Kallien, L.H.; Leis, W. Ageing of zink alloys. Giess. Incl. CD ROM 2011, 63, 2.

30. Park, M.-J.; So, H.; Kang, L.; Byeon, J.-W.; Kim, K.-H. The relation between mechanical properties and microstructural evolution induced by Sc microalloying in Al-20Zn-3Cu alloy. J. Alloys Compd. 2021, 889, 161719. [CrossRef] 